http://aps.journals.ac.za

T. Adeboyejo E I. Onyeonoru: Aspects of Home Environment and Adolescent Sexual Behaviour

\title{
Aspects of Home Environment and Adolescent Sexual Behaviour in Southwestern Nigeria ${ }^{1}$
}

Thompson A. Adeboyejo

Department of Urban and Regional Planning

Ladoke Akintola University of Technology

Ogbomoso. Nigeria
Ifeanyi P. Onyeonoru

Department of Sociology

University of Ibadan, Ibadan

\begin{abstract}
This study examines adolescent sexual behaviour within the context of the home environment (urban low, medium and high residential density) in which the yougsters live. Spatial variations in five variables measuring sexual behaviour: first sex experience, age of first sex, identity of sexual partner, use of family planning (FP) and number of sexual partner were analysed with ANOVA. The data obtained from a survey of 1670 adolescents in two pre-colonial cities in South Western Nigeria reveals that pre-marital sexual relations among urban adolescents is not only becoming a near universal phenomenon, but also the mean age of first sexual encounter is declining. Of great concern is the identity of sexual partners, which now includes commercial sex hawkers. Also noteworthy is the high level of sexual activity with about 3 out of every 4 adolescents having sex with more than one partner in the last six months of the study. These practices are most prominent in the high density home environment. Against the background of observed widespread non-use of FP, the findings of this study raise concern about the public health importance of STIs, and the fact that conventional STIs facilitate the acquisition and transmission of HIV. The need to focus more policy and programme attention on adolescent sexuality behaviour is compelling.
\end{abstract}

\section{Introduction}

Sexual behaviour, like any other social behaviour, is always in a context. It is the interface between structural characteristics of the prevailing socio-cultural situation and the psychological state of the individual. In the adolescent years, the informal context of home environment provides a framework (whether smoothening or constraining) which structures behaviour, perhaps in different ways from the formal contexts of the school and influence of groups and associations in the wider environment.

The home environment, conceived here as the characteristic features of residences, including within-house and immediate neighbourhood conditions in which adolescents live, is not only a projection of family identity, but also an expression or physical translation of cultural believes, practices and behaviour. The identification and categorization of dwelling units in the urban landscape

1 The research on which this article is based was sponsored by Union for African Population Studies (UAPS) under its Small Grants Programme on Population and Development 
permit differentiation of the home environment into residential densities or neighbourhoods. The existence of distinct and recognizable residential neighbourhoods or home environments is one of the overwhelming conclusions in the literature (Abumere, 1992; Oyelese, 1971; Akorede, 1974; Onokerhoraye et al., 1986). The differences in each home environment may be viewed along the lines of household structure, housing type and quality, ownership patterns etc, but all play crucial role in explaining differences in such sexual behavioural characteristics as identity of first sex partner, age of first sex etc, with serious implications for sexual health and well-being.

It is argued here that, the type of home environment as indicated by urban residential neighbourhoods in which adolescents live and possibly work have implications for and may even compound, sexual behaviour among other behavioural dispositions. This is because as an element of complex social interactions taking place within urban milieu, sexual behaviour is not free from both the micro and macro environmental processes that affect the cultural foundation of behavioural disposition. In other words, home environment is an embodiment of micro-environmental processes that affect among other behaviours, sexual behavioural disposition. For instance, in the inner city home environment characterized by planlessness, dilapidated housing conditions, high occupancy ratio etc., the associated poor living and environmental conditions will affect such sexual characteristics as age of first sex, the nature (whether this be by coercion), condition (whether any FP method was used) and process (whether this is by monetary enticement or poverty driven), of first sex experience, as well as identity of first sexual partner (whether this is an older man or woman or a younger sibling). On the other hand, in the well laid-out low-density home environment, characterized by expensive homes and lawns, with where adolescents living in separate rooms, often beyond parental supervising/watchful eyes, and with access to products of modern technology, there is ample opportunity for various sexual experimentations among adolescents (Isiugo-Abanihe \& Oyediran, 2004). The behavioural pattern in the medium density home environment may approximate either the inner city or low-density environmental situation, depending on the strength of the prevailing micro-environmental processes.

The beginning of adolescence is related to the onset of puberty in most cultures, though they may differ widely over when adolescence ends. This is due to the fact that traditions and customs vary so widely from one setting to another that adolescence is difficult to define in universal terms. However, at the 1974 World Health Organisation Meeting on Pregnancy and Abortion in Adolescence, the term was defined as "the period during which an individual progresses from the point of the initial appearance of the secondary sex characteristics to that of sexual maturity. During this period, the individual arrives at a stage of transition from total socio-economic dependence to one of relative independence". For the 
purpose of research, it is common in the literature to restrict operational conceptualisation of the term adolescence to the post pubertal population younger than 20 years of age, (Caldwell et al, 1998). The non-specification of the lower age limit in this case, makes difficult the identification of older children or young adolescents of about 12 years old who in all probability share socio-psychological and biological characteristics with the adolescents proper (13 to 19 years old). Again, the exclusion of those in the 21 to 24 age group also implies removal of "older adolescents" who have striking commonalities with adolescents proper in many respects.

For the purpose of this research, adolescents are identified as those youngsters between the ages of 12 and 24 years. This class of people possess distinctive socioeconomic, and psycho-biological lifestyles characterised by: personality identity search/crises; desire to be free from strict parental control; deviance behaviour, insatiable desire for the excitement and sophistication of modern (urban) life styles etc. The adolescence period has been described as a time of emotional, physical, social and biological development which contributes substantially to the well being of the individual in adulthood (Toitich-Ruto, 1997; Ondimu, 1997)

Our goal in this paper is to examine the relationships between aspects of home environment and adolescent sexual behaviour. By examining inter and intra-city variations in adolescents' sexual behaviour, the specific role of urban home environment, and by logical extension the urban development pattern, on sexual behaviour is examined so as to highlight home environment specific issues in policy and programme formulation.

\section{Data Sources and Methodology}

The data for this analysis were obtained with the aid of a structured questionnaire administered to 1,670 adolescents in two cities - Ibadan and Ogbomoso in southwestern Nigeria. The cities are two of the largest in the region, on account of size, heterogeneity of population and spatial extent. Also, urbanization and urbanism as a way of life of the Yoruba, the main ethnic group in the region, predate European colonization of the country.

For the purpose of data collection, the list of communities (as identified by NPC, 1991) in high, medium and low residential neighbourhoods of each town was first compiled, and from which the communities were randomly selected. Given the differences in population size of the cities and their spatial extent, distribution of questionnaire was based on a ratio of 2 to 1, for Ibadan and Ogbomoso. For distribution of questionnaire among the three commonly recognized home environment types (urban low, medium and high density residential neighbourhoods), to maintain internal (between and within city) consistency, and also conform to the generally believed pattern of population 
distribution within residential areas, a ratio of 3: 2: 1 was employed respectively for high, medium and low density home environments.

\section{Data Analysis}

The data collected were first subjected to descriptive statistics of cross tabulation to determine the level and spatial variations (inter and intra-city) in adolescent sexual behaviour. Five variables measuring sexual behaviour are identified. These are: whether had first sex (Y1); age of first sex experience (Y2); identity of first sex partner (Y3) whether used family planning (FP) method at first sex (Y4); and whether had sex with more than one partner in the last six months (Y5).

In order to analyse the specific role of home environment on sexual behaviour, the method of One-way analysis of variance was employed. This is necessitated by the nominality of the data set, and also since our interest is in data analysis and not synthesis, of a crucially important social phenomenon adolescent sexual behaviour. Each of the three urban home environments (urban high, medium and low densities) was treated as different levels in the ANOVA procedure. The mean differences in variables measuring sexual behaviour among the residential neighbourhoods are examined. The significance of the differences is tested by specifying Scheff'e test in the ANOVA procedure.

\section{Results and Discussion}

\section{Profile of Respondents on the Five Dependent Variables}

\section{Whether Respondents Have Had First Sexual Experience (Y1)}

Table 1 shows that out of the 1633 respondents who answered the question, 937 or 57.4 have had first sexual experience. Ogbomoso with $61 \%$ had higher proportion of respondents that have had first sexual experience relative to Ibadan which had $55.2 \%$. The proportion slightly varies among the three home environments, but in all cases the proportion is more than fifty percent. The data revealed a rising pattern of sexual exposure as residential environment improves, similar to Isiugo-Abanihe and Oyediran's (2004) finding with respect to household socioeconomic status. Compared with a national study (IsiugoAbanihe, 1994) which shows that only $38 \%$ of adolescent respondents were sexually experienced, the findings here shows that sexual intercourse is fast becoming universal among the adolescents in southwestern Nigerian cities. 
Table 1: Percentage distribution of respondents by their sexual experience (Variable Y1)

\begin{tabular}{lrrrrr}
\hline \multirow{2}{*}{ City/Residential Area } & \multicolumn{2}{c}{$\begin{array}{c}\text { Yes, have had Sexual } \\
\text { experience }\end{array}$} & \multicolumn{2}{c}{$\begin{array}{c}\text { No, have not had } \\
\text { Sexual experience }\end{array}$} & \multirow{2}{*}{ Total } \\
\cline { 2 - 4 } Number & \% & Number & \% & \\
\hline Ibadan & 562 & 55.2 & 456 & 44.8 & 1018 \\
Ogbomoso & 375 & 60.9 & 240 & 39.0 & 615 \\
Urban low & 151 & 53.7 & 130 & 46.3 & 281 \\
Medium & 327 & 56.4 & 253 & 43.6 & 580 \\
High & 459 & 59.5 & 313 & 40.5 & 772 \\
Total & 937 & 57.4 & 696 & 42.6 & $1633^{*}$ \\
\hline
\end{tabular}

* Missing Cases $=37$

Source: Adeboyejo and Onyeonoru. (2002)

\section{Age of First Sex (Y2)}

The onset of sexual experience in any society is a pointer to the overall level of sexual health. Early initiation to sexual life and widespread sexual activity among young adolescents portends great danger for the spread of sexually transmitted infections, particularly, given the general disposition of youngsters to unprotected sex. Table 2 reveals that, sexual activities for the youngsters in the study area begin as early as 9 years. In fact, by age 15 (the median age of sexual debut), as high as 54.3 per cent of the respondents had already had their sexual experience. This finding confirms observed early sexual initiation among unmarried youths in the country (Omu et al., 1981; Gyepi Garbrah, 1985), and observed decreasing age of sexual experience for adolescents in parts of Nigeria (NDHS, 1992; Adegbola and Babatola, 1999; Makinwa-Adebusoye and Feyisetan, 1994). There are no discernible inter and intra-urban variations in this observation. Earlier studies, NDHS (1992) and Adegbola et al. (1999) observed median age of 16 for first sexual encounter for Nigerian girls and, males in Lagos state. Comparing the findings here with earlier studies, it can be hypothesized that median age of first sexual encounter among youngsters in the region is declining. 
Table 2: Percentage Variations in Age of First Sexual Experience According to City and Residential Neighbourhoods (Variable Y2)

\begin{tabular}{|c|c|c|c|c|c|c|c|c|c|c|c|c|c|c|c|c|c|c|}
\hline Age & N/A & 9 & 10 & 11 & 12 & 13 & 14 & 15 & 16 & 17 & 18 & 19 & 20 & 21 & 22 & 23 & 24 & Total \\
\hline \multirow[t]{2}{*}{ Ibadan } & 352 & 4 & 5 & 4 & 21 & 18 & 40 & 75 & 77 & 78 & 86 & 41 & 59 & 29 & 15 & 6 & 4 & 914 \\
\hline & 38.5 & 0.4 & 0.5 & 0.4 & 2.3 & 2.0 & 4.4 & 8.2 & 8.4 & 8.5 & 9.4 & 4.5 & 6.5 & 3.2 & 1.6 & 0.7 & 0.4 & 100.0 \\
\hline \multirow[t]{2}{*}{ Ogbomoso } & 246 & 1 & 2 & 2 & 11 & 5 & 12 & 36 & 41 & 58 & 65 & 49 & 50 & 18 & 18 & 4 & 3 & 621 \\
\hline & 39.6 & 0.2 & 0.3 & 0.3 & 1.8 & 0.8 & 1.9 & 5.8 & 6.6 & 9.3 & 10.5 & 7.9 & 8.1 & 2.9 & 2.9 & 0.6 & 0.5 & 100.0 \\
\hline \multirow{2}{*}{ Urban low } & 49 & 1 & - & 2 & 3 & 4 & 9 & 17 & 20 & 24 & 26 & 17 & 12 & 9 & 5 & 2 & - & 200 \\
\hline & 24.5 & 0.5 & - & 1.0 & 0.5 & 2.0 & 4.5 & 8.5 & 10.0 & 12.0 & 13.0 & 8.5 & 6.0 & 4.5 & 2.5 & 1.0 & - & 100.0 \\
\hline \multirow[t]{2}{*}{ Medium } & 225 & 3 & 4 & 2 & 16 & 4 & 13 & 41 & 44 & 41 & 65 & 35 & 32 & 14 & 9 & 3 & 1 & 552 \\
\hline & 40.8 & 0.5 & 0.7 & 0.4 & 2.9 & 0.7 & 2.4 & 7.4 & 8.0 & 7.4 & 11.7 & 6.3 & 5.8 & 2.5 & 1.6 & 0.5 & 0.2 & 100.0 \\
\hline \multirow[t]{2}{*}{ High } & 324 & 1 & 3 & 2 & 13 & 15 & 30 & 53 & 54 & 71 & 60 & 38 & 65 & 24 & 19 & 5 & 6 & 783 \\
\hline & 41.4 & 0.1 & 0.4 & 0.3 & 0.7 & 1.9 & 3.8 & 6.7 & 6.9 & 9.1 & 7.6 & 4.9 & 8.3 & 3.1 & 2.4 & 0.6 & 0.8 & 100.0 \\
\hline \multirow[t]{2}{*}{ Total } & 598 & 5 & 7 & 6 & 32 & 23 & 52 & 111 & 118 & 136 & 151 & 90 & 109 & 47 & 33 & 10 & 7 & 1535 \\
\hline & 39.0 & 0.3 & 0.5 & 0.4 & 2.1 & 1.5 & 3.4 & 7.3 & 7.7 & 8.9 & 9.8 & 5.9 & 7.1 & 3.1 & 2.1 & 0.7 & 0.5 & 100.0 \\
\hline
\end{tabular}

Mean Age of Onset of Sexual Experience 10.54 years; Median Age $=15.0 y r s$.

Source: Adeboyejo and Onyeonoru (2002) 
Table 3 reveals that first sexual partners were mainly boy/girl friends (55.1\%), older man $(2.5 \%)$, older woman $(1.5 \%)$ and commercial sex hawkers $(1.4 \%)$. The table shows that more respondents in Ibadan (57.1\%) compared to Ogbomoso $(42.9 \%)$ patronized commercial sex hawkers. The high density home environment had the greatest proportion of youngsters who patronized commercial sex hawkers $(57.1 \%)$ compared with the proportion in the urban low $(42.9 \%)$ and medium $(14.3 \%)$ density environments. In order to analyse the home environmental correlates of first sex partner, the variable is recoded and weights attached to reflect the probability of contracting STI including HIV. All things being equal, this probability is highest for sexual activity with commercial sex hawker.

Table 3: Percentage Variations in Identity of First Sex Partner by City and Urban Locality

\begin{tabular}{crrrrrrrr}
\hline NA & $\begin{array}{r}\text { Boy/ } \\
\text { Girl } \\
\text { Friend }\end{array}$ & $\begin{array}{r}\text { Older } \\
\text { Woman }\end{array}$ & $\begin{array}{r}\text { Older } \\
\text { Man }\end{array}$ & $\begin{array}{r}\text { Elder } \\
\text { Sis } \\
\text { /Bro }\end{array}$ & $\begin{array}{r}\text { Commercial } \\
\text { Sex } \\
\text { Hawker }\end{array}$ & $\begin{array}{r}\text { Younger } \\
\text { Bro/Sis }\end{array}$ & Total \\
\hline Ibadan & 360 & 510 & 16 & 20 & 8 & 12 & 3 & 929 \\
Row\% & 38.8 & 54.9 & 1.7 & 2.2 & 0.9 & 1.3 & 0.3 & 100.0 \\
Col.\% & 60.2 & 59.7 & 66.7 & 51.3 & 72.7 & 57.1 & 100 & 59.9 \\
Ogbomoso & 238 & 344 & 8 & 19 & 3 & 9 & - & 621 \\
Row\% & 38.3 & 55.4 & 1.3 & 3.1 & 0.5 & 1.4 & - & 100.0 \\
Col.\% & 39.8 & 40.3 & 33.3 & 48.7 & 27.3 & 42.9 & - & 40.1 \\
Urban low & 55 & 128 & 8 & 10 & 2 & 6 & 1 & 210 \\
Row\% & 26.2 & 61.0 & 3.8 & 4.8 & 1.0 & 2.9 & 0.5 & 100.0 \\
Col.\% & 9.2 & 15.0 & 33.3 & 25.6 & 18.2 & 28.6 & 33.3 & 13.5 \\
Medium & 229 & 303 & 6 & 8 & 5 & 3 & 1 & 555 \\
Row\% & 41.3 & 54.6 & 1.1 & 1.4 & 0.9 & 0.5 & 0.2 & 100.0 \\
Col.\% & 38.3 & 35.5 & 25.0 & 20.5 & 45.5 & 14.3 & 33.3 & 35.8 \\
High & 314 & 423 & 10 & 21 & 4 & 12 & 1 & 785 \\
Row\% & 40.0 & 53.9 & 1.3 & 2.7 & 0.5 & 1.5 & 0.1 & 100.0 \\
Col.\% & 52.5 & 49.5 & 41.7 & 53.8 & 36.4 & 57.1 & 33.3 & 50.6 \\
Total & 598 & 854 & 24 & 39 & 11 & 21 & 3 & $1550^{*}$ \\
Row\% & 38.6 & 55.1 & 1.5 & 2.5 & 0.7 & 1.4 & 0.2 & 100.0 \\
Col.\% & 100.0 & 100 & 100 & 100 & 100 & 100 & 100 & 100.0 \\
\hline
\end{tabular}

${ }^{*}$ Missing Cases $=120$

Source: Adeboyejo and Onyeonoru (2002)

\section{Whether Used Family Planning at First Sex (Y4)}

Although 937 or $57.4 \%$ of respondents claimed they had had sexual experience, a total of 954 answered the question on whether they used FP method at first sex. Perhaps this suggests that 17 respondents who had had sexual experience did not answer this question when first asked. 
Table 4 indicates that only 257 or $27.0 \%$ of adolescents used FP method at first intercourse. The proportion is lowest in Ogbomoso (25.0\%) and high density residential areas, also with 25 per cent. This implies that first sex was probably sporadic, unplanned and was probably engaged in at the slightest available opportunity. This is more so given the puritanical stance of the society on issues of pre-marital sex particularly among the segment of the population considered as immature for sexual activity

Table 4: Percentage Distribution of Adolescents by Whether They Used FP Method at First Sex (Y4)

\begin{tabular}{|c|c|c|c|c|c|}
\hline \multirow[t]{2}{*}{ City/Urban Area } & \multicolumn{2}{|c|}{ Yes, used FP } & \multicolumn{2}{|c|}{ No, did not use FP } & \multirow[t]{2}{*}{ Total No } \\
\hline & Number & $\%$ & Number & $\%$ & \\
\hline Ibadan & 162 & 28.0 & 407 & 72.0 & 569 \\
\hline Ogbomoso & 95 & 25.0 & 290 & 75.0 & 385 \\
\hline Urban low & 46 & 30.0 & 106 & 70.0 & 152 \\
\hline Medium & 93 & 28.0 & 239 & 72.0 & 332 \\
\hline High & 118 & 25.0 & 352 & 72.0 & 470 \\
\hline Total & $257^{*}$ & 27.0 & 697 & 73.0 & 954 \\
\hline
\end{tabular}

*Only 257 (27\%) of those who claimed to have had first sexual experience answered the question on whether used FP.

Source: Adeboyejo and Onyeonoru (2002)

Whether Had Sex with more than One Partner (Y5)

Table 5 reveals that about 922 of the total 937 respondents who had had sexual experience answered the question whether had sex with more than one partner. What is evident from the table is the fact that well over half $(66.0 \%)$ of the respondents had had sex with more than one partner in the last six months of the interview. This variable is used as a measure of level of sexual networking, and it is similarly high in the two towns (64.0\%), and highest in the high density home environment areas.

Table 5: Whether Had Sex with More than One Partner (Y5)

\begin{tabular}{|c|c|c|c|c|c|}
\hline \multirow{2}{*}{$\begin{array}{l}\text { City/Urban } \\
\text { area }\end{array}$} & \multicolumn{2}{|c|}{ Yes, } & \multicolumn{2}{|c|}{ No } & \multirow[t]{2}{*}{ Total No } \\
\hline & Number & $\%$ & Number & $\%$ & \\
\hline Ibadan & 354 & 64.0 & 197 & 36.0 & 551 \\
\hline Ogbomoso & 237 & 64.0 & 134 & 36.0 & 371 \\
\hline Urban low & 91 & 62.0 & 56 & 38.0 & 147 \\
\hline Medium & 197 & 62.0 & 122 & 38.0 & 319 \\
\hline High & 303 & 66.0 & 153 & 34.0 & 456 \\
\hline Total & 591 & 66.0 & 331 & 36.0 & 922 \\
\hline
\end{tabular}

Source: Adeboyejoand Onyeonoru (2002) 


\section{Result of ANOVA Test}

The five variables measuring sexual behaviour, as discussed above, constitute the dependent variables, while the three urban home environment areas constitute the groups or levels of ANOVA procedure. The null hypothesis $\mathrm{H}_{0}$ to be tested is that, for each of the five dependent variables, there is no difference in the means of the adolescents in the three residential areas. For significant result, where F probability is less or equal 0.05 , further test of significant pairs is investigated with Scheff'e test.

The result of One-way ANOVA for the five dependent variables is summarized in Table 6. We first consider the non-significant results, which are $\mathrm{Y}_{1}, \mathrm{Y}_{4}$ and $\mathrm{Y}_{5}$ where $\mathrm{F}$ probabilities are respectively $0.28,0.39$ and 0.34 . This implies that for these variables the null hypothesis of no difference in the means of adolescents is upheld. The implications and conclusions are that: First sexual experience is a near universal phenomenon among adolescents, irrespective of the type of home environment, whether it is the high, medium or low density residential neighbourhoods. This is in line with observations that sexual activity is high and may be on the increase among unmarried youths in Nigerian cities (Omu et al., 1981; Gyepi Garbrah, 1985). Secondly, irrespective of the location and environment, most of the adolescents that had had sexual experience did not use any FP method. This practice is similarly common among adolescents in the three home environments.

ANOVA result on $Y_{5}$ implies that, the level of sexual networking is similarly high among adolescents in the three home environments. That is, having sex with more than one partner is a common practice among adolescents in the study area. This observation again confirms earlier report that youngsters in this part of the world do not only practice premarital sex, at an early age, but with multiple partners (Isiugo-Abanihe, 1994; Makinwa-Adebusoye, 1992; IsiugoAbanihe and Oyediran, 2004). This implies that the youths in this part of the country are dangerously exposed to STIs which has as some of its reproductive health implications, miscarriage, infertility and exposure to the spread of HIV/ AIDS with ominous health and socio-economic consequences. 
African Population Studies Vol.20 $n^{\circ}$ 1/Etude de la population africaine vol. $20 n^{\circ} 1$

Table 6: Analysis of Variance: Sexual Behaviour and Adolescents' Home Environment

\begin{tabular}{|c|c|c|c|c|c|c|}
\hline $\begin{array}{l}\text { Source of } \\
\text { Variation } \\
\end{array}$ & D.F. & $\begin{array}{l}\text { Sum of } \\
\text { Squares }\end{array}$ & $\begin{array}{l}\text { Mean } \\
\text { Squares }\end{array}$ & F Ratio & $\begin{array}{l}\text { F } \\
\text { Probability }\end{array}$ & Remark \\
\hline \multicolumn{7}{|c|}{ Whether Had First Sex (Y1) } \\
\hline Between Groups & 2 & 0.6219 & 0.3109 & 1.2711 & 0.2808 & NS \\
\hline Within Groups & 1630 & 398.7364 & 0.2446 & & & \\
\hline Total & 1632 & 399.3582 & & & & \\
\hline \multicolumn{7}{|c|}{ First Sex Age $\left(Y_{2}\right)$} \\
\hline Between Groups & 2 & 25.1564 & 12.5782 & & & \\
\hline Within Groups & 1532 & 3722.8657 & 2.4301 & 5.1761 & 0.0057 & SIG \\
\hline Total & 1534 & 3748.0221 & & & & \\
\hline \multicolumn{7}{|c|}{ First Sex Partner $\left(Y_{3}\right)$} \\
\hline Between Groups & 2 & 7.1107 & 3.553 & & & \\
\hline Within Groups & 949 & 740.8883 & 0.7807 & 4.5540 & 0.0108 & SIG \\
\hline Total & 951 & 747.9989 & & & & \\
\hline \multicolumn{7}{|c|}{ Whether Use FP at First Sex $\left(Y_{4}\right)$} \\
\hline Between Groups & 2 & 0.3640 & 0.1820 & & & \\
\hline Within Groups & 951 & 187.4022 & 0.1971 & 0.9237 & 0.3974 & N.S. \\
\hline Total & 953 & 187.7662 & & & & \\
\hline \multicolumn{7}{|c|}{ Sex than One Partner $\left(Y_{5}\right)$} \\
\hline Between Groups & 2 & 1.9898 & 0.9949 & & & \\
\hline Within Groups & 919 & 846.6913 & 0.9213 & 1.0799 & 0.3401 & N.S. \\
\hline Total & 921 & 848.6811 & & & & \\
\hline
\end{tabular}

Source: Adeboyejo and Onyeonoru (2002)

Table 6 shows that the result of One-way ANOVA on the relationship between first sex age $\left(\mathrm{Y}_{2}\right)$ and first sex partner $\left(\mathrm{Y}_{3}\right)$ and home environment are statistically significant with $\mathrm{F}$ probability in each case less than 0.05 . Thus the null hypothesis in each instance is rejected, implying that the mean score of the respondents on first sex age $\left(Y_{2}\right)$ and first sex partner $\left(Y_{3}\right)$ differ according to home environment.

Results of multiple range tests of significantly different groups of home environment on the significant relationships of Table 6 are shown in Table 7. For the dependent variable - first sex age, Table 7 shows that the low density home environment had the highest mean score of 4.62, followed by high density home environment with 4.56. These means are significantly different from that of adolescents in medium density environment (4.21). This implies that, although mean age of first sex for adolescents is generally low (14-17years), it is lowest for adolescents in the low-density home environment.

The above suggests that age of onset of sexual experience is lowest for adolescents in the low density environment. This is not unexpected, given the exposure of these youngsters to products of modern technology such as sexually provocative phonographic pictures and blue films. The relatively free home 
environment which adolescents in the low density areas enjoy, coupled with their exposure to provocative products of modern technology, permits various forms of sexual experimentation at an early age (an argument also made by Isiugo-Abanihe and Oyediran, 2004).

Table 7: Range of Significant Groups of Home Environment on Sexual Behaviour

\begin{tabular}{|c|c|c|c|c|c|}
\hline \multirow[t]{2}{*}{ Mean } & \multicolumn{2}{|c|}{ Dependent Variables } & \multicolumn{3}{|c|}{ Significant Pairs of Density } \\
\hline & \multicolumn{2}{|c|}{ First Sex Age $\left(Y_{2}\right)$} & & & \\
\hline & Group & Labels & 2 & 1 & 3 \\
\hline 4.2100 & 2 & Medium & & & \\
\hline 4.5581 & 1 & High & - & & \\
\hline \multirow[t]{3}{*}{4.6159} & 3 & Low & - & & \\
\hline & \multicolumn{2}{|c|}{ Identify of First Sex Partner $\left(Y_{3}\right)$} & & & \\
\hline & Group & Labels & 2 & 1 & 3 \\
\hline 1.5786 & 2 & Medium & $\bullet$ & & \\
\hline 1.9152 & 1 & Low & & & \\
\hline 2.4416 & 3 & High & - & & \\
\hline
\end{tabular}

Source: Adeboyejo and Onyeonoru (2002)

However, on the identity of first sex partner, Table 7 shows that the high density home areas had the highest mean score of 2.44 , and this is significantly different only from the mean score of adolescents in the medium density areas (1.58). Given that the higher the mean score the more risky the sexual practice among adolescents, then the observation here shows that the tendency for first sexual partner to be with "strange bedfellows" was more common among adolescents in the high density residential areas.

\section{Conclusions and Policy Implications/Suggestions}

Major findings of this study reveal that pre-marital sex among urban adolescents is not only becoming a near universal phenomenon, age of first sexual encounter is further declining. Of great concern is the identity of sexual partners which has been expanded to include commercial sex hawkers. This practice is particularly common among adolescent in the high density home environment. Also noteworthy is the high level of sexual activity with almost 3 out of every 4 adolescent having sex with more than one partner in the last six months of the study. This practice again is most prominent in the high density environment. Against the background of observed widespread non-use of FP, the findings of this study raise concern about the public health importance of STIs, and the fact that conventional STIs, particularly those that cause genital ulcer disease, facilitate the acquisition and transmission of HIV, the need to focus more policy and programme attention on adolescent sexuality behaviour become more compelling. 
Concern has already been expressed about the fact that urban adolescents continued to record high rates of illegally induced abortion with little regard for their own reproductive health (Makinwa-Adebusoye and Odumosu, 1998) and that unmarried girls in Ibadan city were twice as likely to be practicing contraception as married women, in spite of the refusal of hospitals and family planning clinics to provide services for the single (Caldwell et al., 1992). As also observed in a related work, the essence of puritanical relationships between opposite sexes which is an important component of indigenous cultural heritage is being deconstructed rapidly in the minds of the youngsters by products of modern technology (Adeboyejo and Onyeonoru, 2003). The slackening of traditional requirement for pre-marital chastity, poverty, peer pressure, wrong or lack of knowledge about reproductive biology, play crucial role in explaining prevalence of premarital sexuality. The fact is that adolescent population is one of the high risk groups for HIV transmission; they are not only sexually active, but are also involved in behaviours that put them at risk for HIV/ AIDS.

There is thus the need to re-examine national health policies and programmes such that adolescents' health and well-being are given more attention, perhaps in a similar way to health policies and programmes aimed at children. This is because, the available evidences point to the fact that the adolescent population may be most infected and impacted by the scourge of HIV/AIDS. According to President Olusegun Obasanjo (Aug. 4, 2003) "out of 28 million people living with HIV/AIDS in Sub-Saharan Africa, 4 million (14.3\%) are Nigerians. Of the Nigerians living with the deadly disease, a staggering 800,000 or 20 per cent are children. The significance of these statistics becomes more evident if we note that Nigeria has a youthful population structure, in which more than $40 \%$ of the population is under the age of 20 years (NDHS, 1990).

As a matter of policy, there is the need to identify adolescents in major activity areas in the city, such as motor parks, restaurants etc. as "youths at risk for HIV/AIDs". Government hospitals and clinics should be more youthfriendly, and the youth should be benefit form a highly subsidized, if not free, general medical services, including sex-related health care. This implies equipping the hospitals to provide case management, HIV counseling and testing, risk education activities, information, education and training.

A unit of government hospitals should provide teen-focused extension services and outreaches to youths in different urban neighbourhoods and areas where high risk youths congregate. This is aimed at expanding and ensuring access to health and support services for adolescents at risk of HIV. Peer educators should be recruited from the local community, trained and paired with staff to provide peer counseling and education as well as to assist with recreational and vocational activities. 
The support and cooperation of Family/Life Planning Associations, Non-Governmental Organisations and Community Based Associations are highly essential. Sine they are closer to the people, they should source for funds from donor agencies, play advocacy roles in issues concerning adolescent sexuality and reproductive health and assist in implementing effective HIV prevention programmes for adolescents in order to change their attitudes and behaviours.

\section{References}

Abumere S.I 1982. "Residential Differentiation in Ibadan: some Sketches of an Explanation" in: Filani, M.O (ed.), Ibadan Region, Department of Geography, University of Ibadan. Ibadan

Adeboyejo, A.T. \& I. P. Onyeonoru. 2002. "Urban Residential Density and Adolescent Sexuality and Reproductive Health in Oyo State, Nigeria". A Research Report Submitted to Union for Africa Population Studies (UAPS), Dakar, Senegal.

Adeboyejo, A.T. and I. P. Onyeonoru 2003 "Residential Density and Adolescent Reproductive Health Problems in Ibadan, Nigeria". African Population Studies, 18(1): 81-95. UAPS, Dakar.

Adegbola O. and Babatola O. 1999 "Premarital and Extramarital Sex in Lagos, Nigeria", in Orubuloye I.O. , Caldwell J.C. , Ntozi J.P.M. The Continuing HIV/AIDS Epidemic in Africa: Responses and Coping Strategies, Health Transition Center, National Center for Epidemiology and Population Health, Australian National University, Camberra.

Caldwell J.C., Orubuloye J.O and Caldwell P. 1992. "Fertility Decline in Africa: A New Type of Transition"? Population and Development Review Vol. 18, No 2, June.

, Pat Caldwell, B.K. Caldwell and Indrani Pieris (1998) "The Construction of Adolescence in a Changing World". Studies in Family Planning. 9(2 1):137 - 153.

Gerald, K. H. 1978 "Intra-Urban Variation in Kampung Settlement in Jakarta: A Structural Analysis". Journal of Tropical Geography, vol. 46, June, 1978

Gyepi-Garbrah, B. 1985. Adolescent Fertility in Sub-Sahara Africa: An Overview. The Pathfinder Fund, Boston, Massachusetts.

Isiugo-Abanihe Uche. 1994. "Correlates of Pre-marital Sexuality in Nigeria" African Journal for the Psycological Study of Social Issues, 1(2): 257-276.

Isiugo-Abanihe, Uche and Oyediran, Kola. 2004. "Household socioeconomic status and sexual behaviour among Nigerian female youth" African Population Studies, 19(1):8198.

Makinwa Adebusoye, P. 1992. "Sexual Behaviour, Reproductive Knowledge and Contraceptive Use among Young Urban Nigerians" International Family Planning Perspective, 18(2): 66-70

Makinwa Adebusoye and Feyisetan, B.J. 1994. "The Quatum and Tempo of Fertility in Nigeria" In: DHS Regional Workshop for Anglophone Africa - Fertility Trends and Determinants in Six African Countries, Macro International Inc., Calverton, April, pp. 41-86

Nigerian Demographic and Health Survey (1990), Federal Office of Statistics, Lagos.

National Population Commission. Census of Nigeria. 1991. Abuja: NPC

Omu, A.E et al. 1981. "Adolescent Induced Abortion in Benin City, Nigeria”, Journal of Gynaecology EObstetrics., 21. 
African Population Studies Vol.20 $n^{\circ} 1 /$ Etude de la population africaine vol. $20 n^{\circ} 1$

Onokerhoraye, A.G. and Omuta, G.E.D 1986 Urban Systems and Planning. Methuen, Benin Ondimu K.N, (1997) "The Determinants of Adolescent Reproductive Health Problems in Kenya: Evidence from Health Services Data." African Population Studies, 12(2):51- 64.

Oyelese, J.T. 1971 "The Growth of Ibadan City and its Impact on Landuse Patterns," Journal of Tropical Geography. Vol. 38 no.3 Methuen pp 6-30

President Olusegun Obasanjo 2003 “800,000 Kids Have AIDS in Nigeria” an Address to Permanent Secretaries in Nigeria. Nigerian Tribune, Tuesday August 5, 2003

Torotich-Ruto Cathy (1997) "The Determinants of Teenage Sexuality and their Understanding of STDs/HIV/AIDS in Kenya." African Population Studies, 12(2): 39- 50. 